\title{
Comportamento de bugio-ruivo (Alouatta guariba clamitans, Cabrera, 1940) sob cuidados humanos com aplicação de enriquecimento ambiental
}

\author{
SIPPLI, Christine Ebeling1; HIPPÓLITO, Alícia Giolo2; TESTA, Carolyne Assis Eigenheer Pinke²; \\ CASTRO, Thiago Ferla Novais ${ }^{3}$; MILANELO, Liliane ${ }^{4}$; LOURO, Mônica Ponz ${ }^{5}$
}

\footnotetext{
${ }^{1}$ Estagiária do Centro de Reabilitação de Animais Silvestres do Parque Ecológico do Tietê (CETAS - PET), Bolsista Centro de Integração Empresa-Escola (CIEE), Graduanda em Ciências Biológicas - Bacharelado, Universidade Presbiteriana Mackenzie, São Paulo/SP.

${ }^{2}$ Pós-graduação em Animais Selvagens, Faculdade de Medicina Veterinária e Zootecnia, UNESP, Botucatu/SP, Departamento de Clínica Veterinária.

${ }^{3}$ Graduando em Ciências Biológicas - Bacharelado, Universidade do Sagrado Coração, USC, Bauru/SP.

${ }^{4}$ Coordenadora e Médica Veterinária, Parque Ecológico do Tietê e Centro de Recuperação de Animais Silvestres, São Paulo/SP.

${ }^{5}$ Docente, Universidade Presbiteriana Mackenzie, São Paulo/SP.

Email: christine.sippli@usp.br
}

RESUMO: Medidas de enriquecimento ambiental são necessárias para propiciar modificações no recinto que o deixem mais dinâmico e estimulante, visando comportamentos dos indivíduos mais semelhantes aos apresentados pela espécie em vida livre. O objetivo deste trabalho foi analisar o comportamento de bugiosruivos, por meio da aplicação de enriquecimentos ambientais dos tipos alimentar, cognitivo e sensorial. Foram observados os comportamentos de um grupo de bugios subadultos e um de bugios adultos por dez minutos antes da instalação do enriquecimento (pré-enriquecimento) e dez minutos após sua instalação (pósenriquecimento), totalizando 10 horas de registros comportamentais. Os resultados mostram que as reações dos animais à aplicação do enriquecimento do tipo alimentar foram mais efetivas pelos dois grupos, obtendo-se maior sucesso, porém é importante mencionar que estudos com diversos tipos de enriquecimento ambiental são fundamentais, visto que por meio destes, é possível avaliar o bemestar de cada indivíduo e determinar quais devem ser mais utilizados em função das principais necessidades individuais.

Palavras-chave: bem-estar; cognitivo; enriquecimento ambiental nutricional.

\section{INTRODUÇÃO}

O A. guariba clamitans (Cabrera, 1940) é sempre associado ao bioma Mata Atlântica. Segundo KUGELMEIER (2005), os bugios são animais diurnos, sendo mais ativos no meio da manhã e no meio da tarde. Seus hábitos alimentares estão relacionados ao consumo de folhas e frutos, podendo ser incluídos flores, sementes e brotos.
Os bugios são animais pouco ativos, que passam a maior parte do tempo em descanso, o que pode ser relacionado com essa dieta, que é pouco energética (MIRANDA, 2004). Os bugios formam grupos com indivíduos de ambos os sexos, de diferentes idades, em média, de 4 a 10 animais, tendo um macho dominante, machos subordinados, subadultos e em sua maioria fêmeas (BUSS, 2001; HIRANO, 2003; 
KUGELMEIER, 2005). A sua vocalização tem um importante papel de espaçamento intergrupal e acesso a fontes de alimentos preferidos, pois representam uma exibição agressiva perante os indivíduos do outro grupo (DALMASO e CODENOTTI, 2010; CHIQUITELLI NETO et al., 2011; DECKER, 2013). Em cativeiro, como forma de proteção ao estresse e prevenção de comportamentos anormais à espécie, sugere-se o uso de práticas de técnicas de enriquecimento ambiental, sendo que o uso do enriquecimento ambiental do tipo alimentar é válido em conjunto com outras medidas de enriquecimento (VASCONCELLOS e ADES, 2012).

Assim, o objetivo deste trabalho foi realizar uma análise comportamental de bugios-ruivos por meio da comparação das observações obtidas de comportamentos realizados antes da estimulação do enriquecimento ambiental e a partir da instalação de recursos de enriquecimento nos recintos.

\section{MATERIAL E MÉTODOS}

Um grupo de sete bugios subadultos (seis machos e uma fêmea) e um outro grupo de dois bugios machos adultos, mantidos em recintos de $9 \mathrm{~m}^{2}$ no Centro de Recuperação de Animais Silvestres do Parque Ecológico do Tietê foram observados das $12 \mathrm{~h}$ às $17 \mathrm{~h}$, uma a três vezes por semana. Não foram realizadas observações em dias de chuva, pois a condição climática pode alterar o comportamento dos animais. Foram elaborados três diferentes tipos de enriquecimento ambiental nos recintos: o primeiro enriquecimento, do tipo alimentar e denominado "Caixa de Folhas", constituía-se de uma caixa de papelão com uma abertura frontal, preenchida com folhas de hibisco (Hibiscus rosasinensis) e amora (Morus nigra), colocada amarrada em cima dos recintos. Para 0 segundo enriquecimento, do tipo cognitivo, foi elaborada uma caixa de madeira MDF, pintada na cor verde, com um puxador de gavetas prateado, para destaque do mecanismo de abertura da caixa, e foram inseridas frutas, folhas de amora e hibiscos, sendo, então, colocada no chão do recinto. Para o terceiro enriquecimento, do tipo sensorial, foi utilizado um telefone celular com a gravação das vocalizações da espécie estudada, para, assim, identificar possíveis modificações de comportamento dos animais ao ouvirem as gravações. As observações foram divididas em dois momentos, préenriquecimento e pós-enriquecimento, e cada período contou com observações contínuas de dez minutos, sendo anotado, a cada minuto, o comportamento apresentado. Foi realizado o método de varredura instantânea (CASTRO, 2010) em ambos os recintos. Foram totalizadas 15 observações por recinto, e cada enriquecimento foi realizado cinco vezes em cada recinto. Os indivíduos jovens foram agrupados para análise, pois apresentaram comportamento semelhante; os adultos, por terem apresentado comportamentos distintos, foram separados em Adulto 1 e Adulto 2.

\section{RESULTADOS E DISCUSSÃO}

Foi possível notar que o grupo de indivíduos jovens no período anterior à aplicação do enriquecimento apresentava um maior número de registros de locomoção e de permanecer parado, sendo que estas atividades diminuíram drasticamente após a introdução do enriquecimento. Com relação ao indivíduo Adulto 1 , que anteriormente se encontrava preferencialmente parado, com a introdução do enriquecimento 
apresentou também muita interação, com cerca de $70 \%$ das performances. De modo muito diferente, o Adulto 2 não interagiu tanto com o enriquecimento (apenas 31\% de comportamentos de interação) realizando, em parte, o que já apresentava antes do enriquecimento. A diferença de padrões comportamentais em relação ao indivíduo Adulto 2 pode ser explicada pela possível dominância do Adulto 1 sobre o Adulto 2, de modo que este último se afastava do local onde estava o objeto de enriquecimento enquanto 0 indivíduo dominante interagia com o mesmo. É importante mencionar que, em uma das observações referentes a este enriquecimento, foi constatado que 0 indivíduo dominante teve um comportamento agressivo perante 0 submisso, devido à sua aproximação do objeto de enriquecimento, 0 que resultou no distanciamento do mesmo e sua locomoção para a toca. Observouse também, por alguns minutos, que o macho submisso se alimentava de folhas que o macho dominante havia deixado cair no chão do recinto. O Adulto 1 pode ser reconhecido como sendo o indivíduo dominante também devido ao maior número de vocalizações emitidas, quando comparado com o Adulto 2, que pouco realizou esse comportamento. De acordo com Dalmaso e Codenotti (2010), geralmente o comportamento agressivo de bugios pela busca de recursos, o maior tamanho corporal, a força e a juventude são características que determinam o grau de hierarquia social em um grupo, visto que possibilitam 0 animal ser mais capacitado à competição. Também foi observado que o Adulto 2 realizou comportamentos estereotipados de pacing durante o período de pósenriquecimento, 0 que pode ser entendido como mais uma evidência de uma situação de desconforto e estresse.

\section{CONCLUSÃO}

Em todos os enriquecimentos ambientais empregados, houve interação entre os animais dos recintos. A maioria dessas interações foi observada no recinto dos indivíduos jovens. Assim, propõe-se que os enriquecimentos ambientais sejam aplicados prioritariamente para os bugios adultos, que necessitam de um estímulo maior.

\section{AGRADECIMENTOS}

Os autores agradecem ao CETAS - PET pela oportunidade, disponibilização dos animais e estrutura para a realização deste trabalho.

\section{REFERÊNCIAS}

BUSS, G. Estudo da Densidade Populacional do bugio-ruivo Alouatta guariba clamitans (Cabrera, 1940) (Primates, Atelidae) nas Formações Florestais do Morro do Campista, Parque Estadual de Itapuã, Viamão, RS. Dissertação de Mestrado. Programa de Pós-graduação em Ecologia. Instituto de Biociências. Universidade Federal do Rio Grande do Sul. Porto Alegre, 2001. 69p.

CASTRO, C. S. S. Pesquisa com primatas em ambiente natural: técnicas para coleta de dados ecológicos e comportamentais. 62 $2^{\underline{a}}$ Reunião da Sociedade Brasileira para Congresso da Ciência - SBPC. Natal - RN. Departamento de Engenharia e Meio Ambiente. Centro de Ciências Aplicadas e Educação. UFPB, Campus IV - Rio Tinto, PB. 2010. 27p.

CHIQUITELLI NETO, M.; KANDA, C. Z.; DORIA, E. C.; ZAMARRENHO, L. G.; GONÇALVES, F. H. P. Avaliação do bem-estar de um bugio (Alouatta caraya) cativo durante enriquecimento social e ambiental: indicadores 
comportamentais. Revista de Etologia, v. 10, n. 1, p. $12-20,2011$.

DALMASO, A. C.; CODENOTTI, T. L. Comportamentos de hierarquia e dominância em grupos de bugios-ruivos, Alouatta guariba clamitans (Cabrera, 1940) em cativeiro. Revista de Etologia, v. 9 , n. 2, p. 40-47, 2010.

DECKER, E. B. Ecologia e comportamento de bugio-ruivo (Alouatta guariba clamitans) em um fragmento florestal no limite sul da distribuição: testando predições de modelos socioecológicos. Dissertação de Mestrado. Programa de Pós-graduação em Zoologia. Faculdade de Biociências da Pontifícia Universidade Católica do Rio Grande do Sul. Porto Alegre, 2013. $54 p$.

HIRANO, Z. M. B. Secreção epidérmica de Alouatta guariba clamitans (Primates: Atelidae). Programa de Pós-graduação em Biologia Comparada. FFCLRP Departamento de Biologia. Universidade de São Paulo. Ribeirão Preto, 2003. $146 \mathrm{p}$.

KUGELMEIER, T. Avaliação Endocrinológica do ciclo ovariano do macaco bugio (Alouatta caraya Humboldt, 1812) por meio de extração e dosagem de metabólitos de esteroides fecais. Dissertação de Mestrado. Programa de Pós-graduação em Reprodução Animal da Faculdade de Medicina Veterinária e Zootecnia da Universidade de São Paulo. São Paulo, 2005. 120p.

MIRANDA, J. M. D. Ecologia e Conservação de Alouatta guariba clamitans Cabrera 1940 em Floresta Ombrófila Mista no Estado do Paraná, Brasil. Dissertação de Mestrado em Ciências. Curso de Pós-graduação em Zoologia. Setor de Ciências Biológicas.
Universidade Federal do Paraná. Curitiba, 2004. 83p.

VASCONCELLOS, A. S.; ADES, C. Possible limits and advances of environmental enrichment for wild animals. Revista de Etologia, v. 11, n. 1, p. 37-45, 2012.

Agradecemos ao apoio da Fundação Araucária e da Coordenação de Aperfeiçoamento de Pessoal de Nível Superior - CAPES na realização do $3^{\circ}$ Workshop de Nutrição de Animais Selvagens.
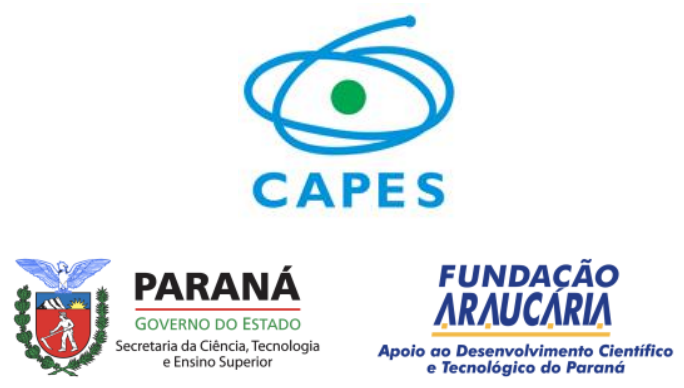